\title{
HapMap-based study of the 17q2I ERBB2 amplicon in susceptibility to breast cancer
}

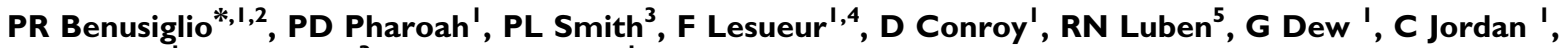 A Dunning ${ }^{1}$, DF Easton ${ }^{3}$ and BAJ Ponder'}

'Strangeways Research Laboratory, Cancer Research UK Department of Oncology, University of Cambridge, Strangeways Research Laboratory, Worts Causeway, Cambridge CBI 8RN, UK; ${ }^{2}$ Department of Internal Medecine, Hôpital Cantonal Universitaire de Genève, 24 rue Micheli-du-Crest, 1211 Genève 14, Switzerland; ${ }^{3}$ Department of Genetic Epidemiology, University of Cambridge, Strangeways Research Laboratory, Worts Causeway, Cambridge CBI 8RN, UK; ${ }^{4}$ Génomes et Cancers, Institut de Cancérologie Gustave Roussy, rue Camille Desmoulins, 94805 Villejuif, France; ${ }^{5}$ EPIC, University of Cambridge, Strangeways Research Laboratory, Worts Causeway, Cambridge CBI 8RN, UK

ERBB2 is frequently amplified in breast tumours as part of a wide region of amplification on chromosome 17q21. This amplicon contains many candidate genes for breast cancer susceptibility. We used a genetic association study design to determine if common genetic variation (frequency $\geqslant 5 \%$ ) in a 400-kb region surrounding ERBB2 and containing the PPARBP, CRK7, NEUROD2, PPPIRIB, STARD3, TCAP, PNMT, CAB2, ERBB2, CI 7ORF37, GRB7 and ZNFNIA3 genes, was associated with breast cancer risk. Sixteen tagging single-nucleotide polymorphisms (tSNPs) selected within blocks of linkage disequilibrium from the HapMap database, one HapMap singleton SNP, and six additional SNPs randomly selected from dbSNP were genotyped using Taqman in a large study set of British women (2275 cases, 2280 controls). We observed no association between any of the genotypes or associated haplotypes and disease risk. In order to simulate unidentified SNPs, we performed the leave-one-out cross-validation procedure on the HapMap data; over $90 \%$ of the common genetic variation was well represented by tagging polymorphisms. We are therefore likely to have tagged any common variants present in our population. In summary, we found no association between common genetic variation in the $17 \mathrm{q} 21$ ERBB2 amplicon and breast cancer risk in British women.

British Journal of Cancer (2006) 95, I689-1695. doi:I0.1038/sj.bjc.6603473 www.bjcancer.com

Published online 2I November 2006

(c) 2006 Cancer Research UK

Keywords: breast neoplasms; ERBB2; amplicon; genetic susceptibility; single-nucleotide polymorphism; HapMap

Only a small proportion of the excess familial risk associated with breast cancer is accounted for by known highly penetrant genes, $B R C A 1$ and BRCA2. The remainder is probably due to a combination of weakly predisposing alleles including both common and rare variants (Pharoah et al, 2002; Dite et al, 2003). We have previously shown that common alleles in ERBB2 are not involved in breast cancer susceptibility (Benusiglio et al, 2005). However, ERBB2 is part of a wider region of chromosome $17 \mathrm{q} 21$ frequently amplified in breast cancer. This amplicon encompasses many genes and it is conceivable that, as suggested by the variability of response to anti-ERBB2 therapy in patients with $E R B B 2$ amplification, more than one gene in the amplicon could contribute to breast cancer susceptibility, development and progression (Willis et al, 2003).

Kauraniemi et al (2001, 2003) first carried out a systematic survey of copy number and expression patterns in all genes within the 17q21 locus on breast cancer cell lines and tumour samples; they identified a 200-kilobase $(\mathrm{kb})$ minimal common region of

*Correspondence: Dr PR Benusiglio, Department of Internal Medecine, Hôpital Cantonal Universitaire de Genève, 24 rue Micheli-du-Crest, 121 I Genève 14, Switzerland; E-mail: pbenusiglio@yahoo.com

Received 30 May 2006; revised 9 October 2006; accepted 13 October 2006; published online 21 November 2006 amplification around ERBB2 containing the following genes: neurogenic differentiation 2 (NEUROD2), protein phosphatase 1 regulatory subunit $1 \mathrm{~B}(P P P 1 R 1 B)$, START domain containing 3 (STARD3), titin-cap (TCAP), phenylethanolamine- $N$-methyltransferase (PNMT), CAB2 (Per1-Like Domain Containing 1 [PERLD1]), C17ORF37, growth factor receptor-bound protein 7 (GRB7) and zinc-finger protein subfamily $1 \mathrm{~A} 3$ (ZNFN1A3).

Gene expression levels in cancer cells together with knowledge about protein function can help in assessing which genes are involved in oncogenesis (Futreal et al, 2004). For example, STARD3, PNMT, CAB2, C17ORF37 and GRB7 show a significant correlation between amplification status and expression level (Kauraniemi et al, 2001, 2003; Willis et al, 2003; Orsetti et al, 2004), and STARD3, PNMT, CAB2, GRB7 and ZNFN1A3 could all be biologically relevant to breast cancer. $S T A R D 3$ mediates intracellular trafficking of cholesterol and can augment steroid hormone synthesis (Strauss, III et al, 2003). Overexpression of PNMT results in suppression of circulating leptin levels - a potent regulator of body weight - in transgenic mice (Bottner et al, 2000; Harvey and Ashford, 2003). CAB2 is a human homologue of the yeast COS16 gene required for the repair of DNA double-strand breaks (Nezu et al, 2002) and GRB7 regulates cell migration through its involvement in cell signalling pathways (Han et al, 2001). Finally, ZNFN1A3 appears to function as a tumour suppressor since its 
downregulation in the mouse leads to leukaemias and lymphomas (Rebollo and Schmitt, 2003).

Two neighbouring genes, peroxisome proliferator-activated receptor binding protein $(P P A R B P)$ and $C D C 2$-related protein kinase 7 (CRK7), located about $50 \mathrm{~kb}$ upstream from NEUROD2 the first gene on the minimum region of amplification - are often, although less consistently, co-amplified with ERBB2 (Kauraniemi et al, 2001, 2003). Both are potentially implicated in cancer biology. $P P A R B P$, by its ability to function as an oestrogen receptor coactivator, might play a role in mammary epithelial differentiation (Zhu et al, 1999) while CRK7 could link transcription with the splicing machinery (Ko et al, 2001).

The case-control study design is well suited to the identification of small-effect genes that are likely to underlie common, complex diseases such as breast cancer (Risch, 2000). Two approaches have been proposed. The direct, hypothesis-driven approach is to investigate single nucleotide polymorphisms (SNPs), which are thought to have functional effects and thus influence directly the traits under study (Tabor et al, 2002). The indirect, tagging approach is to select a set of empirical tagging SNPs (tSNPs) that best capture the common genetic variation within the gene. They serve as markers to detect associations between a particular region and diseases, whether or not the tSNPs themselves have a functional effect (Gabriel et al, 2002). It is not necessary to genotype all polymorphisms because the alleles of SNPs that are physically close to each other tend to be correlated with each other: they are in linkage disequilibrium (LD) (Pharoah et al, 2004). The HapMap online database (http://www.hapmap.org) allows the tagging approach to be applied readily to many genes or regions (Gibbs et al, 2003). By March 2006, the database held the genotypes of individuals with European, African-American, and Asian ancestry for nearly four million SNPs.

We aimed to determine whether common genetic variation (frequency $>5 \%$ ) in the ERBB2 amplicon is involved in breast cancer susceptibility. We used HapMap data to identify tSNPs for genotyping in a large breast cancer case-control study of white British women. Data for five of the SNPs described in this report have been previously published (Benusiglio et al, 2005), but are also included here for completeness.

\section{METHODS}

\section{Patients and controls}

Cases were drawn from SEARCH, an ongoing population-based study in which cases are ascertained through the East Anglian Cancer Registry. All patients diagnosed with invasive breast cancer below age 55 years since 1991 and still alive in 1996 (prevalent cases; median age 48 years), together with all those diagnosed $<70$ years between 1996 and the present (incident cases; median age 52 years), were eligible to take part. All study participants completed an epidemiological questionnaire and provided a blood sample for DNA analysis. Sixty-seven percent of eligible breast cancer patients returned a questionnaire and $64 \%$ provided a blood sample. Controls were randomly selected from the Norfolk component of EPIC (European Prospective Investigation of Cancer). EPIC is a prospective study of diet and cancer being carried out in nine European countries. The EPIC-Norfolk cohort comprises 25000 individuals resident in Norfolk, East Anglia, the same region from which the cases have been recruited. Controls are not individually matched to cases, but are broadly similar in age, being aged $42-81$ years. The ethnic background of both cases and controls as reported on the questionnaires is similar, with $>98 \%$ being white. All participants have given written consent and the study is approved by the Eastern Region Multicentre Research Ethics Committee.

A total of 4474 cases, of whom $27 \%$ were prevalent cases, and 4560 controls, were available for analysis. The samples have been split into two sets in order to conserve DNA and reduce genotyping costs. The first set (2275 cases, 2280 controls) is genotyped for all SNPs. Any SNP that shows association in set 1 at the $P<0.1$ level, can then be tested in the second set $(2199$ cases, 2280 controls). This staged approach substantially reduces genotyping costs without significantly affecting statistical power (see below). Cases with high yields of genomic DNA were selected for set 1 from the first 3500 recruited, with set 2 comprising the remainder of these plus the next 974 incident cases recruited. As the prevalent cases were the first recruited, the proportion of prevalent cases was somewhat higher in set 1 than set 2 (33 vs $20 \%)$. Median age at diagnosis was similar in both sets (51- and 52year-old, respectively). Median time from diagnosis to blood draw was slightly longer for set 2 (15 months) than for set 1 (9 months). There were no significant differences in the morphology, histopathological grade or clinical stage of the cases by set or by prevalent/incident status.

\section{SNP identification and selection}

The amplicon of interest is a $400-\mathrm{kb}$ region, with $P P A R B P$ in position $5^{\prime}$ and ZNFN1A3 in position $3^{\prime}$ (Figure 1). A $50-\mathrm{kb}$ segment located between CRK7 and NEUROD2 was excluded as it contained no known gene, splitting the amplicon into a $150-\mathrm{kb}$ region including PPARBP and CRK7 (region A) and a $200-\mathrm{kb}$ region including NEUROD2, PPP1R1B, STARD3, TCAP, PNMT, $C A B 2, E R B B 2, C 17 O R F 37, G R B 7$ and ZNFN1A3 (region B).

We used data on common SNPs from HapMap (European samples, public release \#15) to identify tSNPs. After exclusion of one singleton SNP that was poorly linked with any other SNP ( ${ }^{\prime}$ $<0.3$ ), blocks of LD were defined on the basis of limited haplotype diversity (common haplotypes must account for at least $90 \%$ of all haplotypes) (Cardon and Abecasis, 2003). tSNPs were selected within blocks using the tagSNPs program so that unmeasured

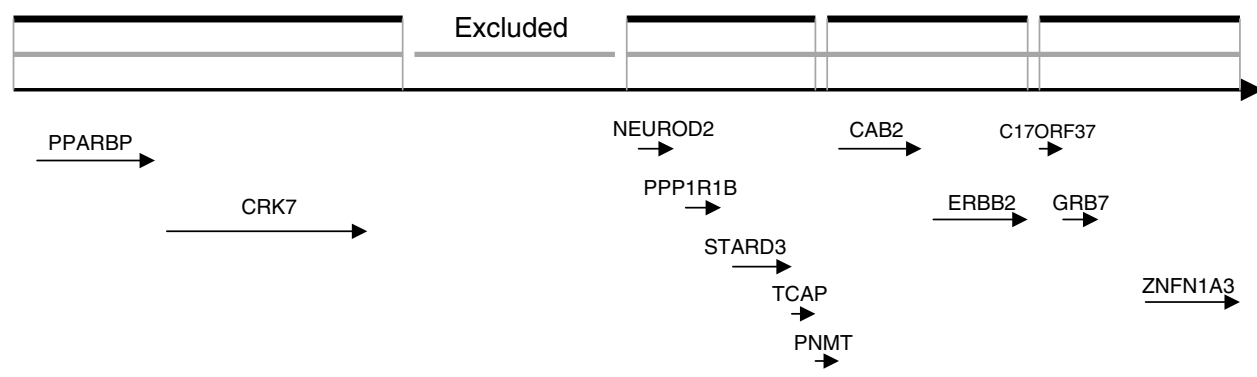

Figure I The 400-kb ERBB2 amplicon. It is split in two (regions $\mathbf{A}$ and $\mathbf{B}$ ) by a 50-kb segment containing no known gene. Region $\mathbf{A}$ consists of one LD block while region $\mathbf{B}$ consists of three blocks, blocks 2, 3 and 4 . 
SNPs were tagged with a minimum $r_{\mathrm{s}}^{2}$ of 0.8 (Stram, 2004). The $r_{\mathrm{s}}^{2}$ coefficient measures LD between unmeasured SNPs and haplotypes defined by the selected tSNPs. The five ERBB2 SNPs previously genotyped (ERBB2-01 to -05) were forced as tSNPs into the selection algorithm and SNPs surrounded by repetitive DNA sequences were excluded (they could not be selected as tSNPs). The average SNP density of the HapMap SNPs was 1 SNP/ $5 \mathrm{~kb}$. In order to increase the SNP density and improve the tagging properties of our SNP set, we also selected at the beginning of the study additional random, validated polymorphisms from the dbSNP database (http://www.ncbi.nlm.nih.gov/projects/SNP).

\section{Genotyping}

Genotyping was carried out using Taqman (Applied Biosystem, Warrington, UK). Primers and probes were supplied directly by Applied Biosystems, except those for ERBB2-04 and -05 that were designed 'in-house' with the Primer Express Oligo Design Software v2.0 (Applied Biosystems). Sequences are available on request. Reactions were carried out at 54 or $60^{\circ} \mathrm{C}$ in 384 -well plates with cases and controls plated together. Each plate included two negative controls with no DNA and 12 samples duplicated on a separate quality control plate. Plates were read on the ABI Prism 7900 using the Sequence Detection Software (Applied Biosystems). Complete concordance between samples and their duplicates, excluding undetermined genotypes, was required for the assay to be validated. Failed genotypes were not repeated.

\section{Statistical methods}

For each SNP, deviation of genotype frequencies in controls from Hardy-Weinberg (HW) equilibrium was assessed by a standard $\chi^{2}$ test ( 1 degree of freedom (df)). Genotype frequencies in cases and controls were compared by a $\chi^{2}$ test for heterogeneity ( $2 \mathrm{df}$ ). Genotype-specific risks were estimated as odds ratios (OR) using standard cross-product ratio and confidence intervals were calculated using the variance of the log (OR), which was estimated by the standard Taylor expansion. A comparison of haplotype frequencies between cases and controls was carried out using the haplo.score routine implemented in S-plus (Schaid et al, 2002). Haplotypes with an estimated frequency of $<5 \%$ were pooled. Haplo.score uses a likelihood that depends on estimated haplotype frequencies to test the statistical association between haplotypes and phenotype. It is based on score statistics, which provide both global tests and haplotype-specific tests.

\section{RESULTS}

The HapMap release \#15 included genotypes for 66 common SNPs (26 in region A and 40 in region B). Region A consisted of only one LD block, block 1 with 26 SNPs, whereas region B consisted of three blocks, block 2 with 14 SNPs, block 3 with 11 SNPs and block 4 with 15 SNPs. One singleton SNP, ERBB2-04 (I655V), was excluded from block 3, leaving 10 SNPs in block 3. Block 1 included $P P A R B P$ and $C R K 7$, block 2 included NEUROD2, $P P P 1 R 1 B, S T A R D 3$ and TCAP, block 3 included $C A B 2$ and ERBB2 and block 4 included C17ORF37, GRB7 and ZNFN1A3 (Figure 1).

Sixteen tSNPs were selected for genotyping: four in block 1, three in block 2, five in block 3 and four in block 4 (Table 1). ERBB2-04 - the HapMap singleton SNP - and six additional SNPs randomly selected from dbSNP (one in block 2, four in block 3 and one in block 4) were also genotyped. None of the genotype distributions in controls differed significantly from those expected under HW equilibrium. There was no evidence that any of the SNPs is associated with breast cancer, and none of the SNPs exceeded the significance threshold for genotyping in the second set of cases and controls (Table 2). The genotype-specific ORs were all close to unity with confidence intervals including one (Figure 2). The tSNPs generated five common haplotypes in block 1 , three in block 2, four in block 3 and four in block 4 (Table 3). The global test of association was not significant for any of the four blocks $(P=0.16,0.58,0.48$ and 0.44 for blocks $1,2,3$ and 4 , respectively),

Table I SNPs selected for genotyping, the database they were selected from, the LD block to which they belong, their location within genes and their frequencies in databases

\begin{tabular}{|c|c|c|c|c|c|c|}
\hline SNP & rs number & Database & Block & Location & Base change & MAF \\
\hline PPARBP-0I & rs65035। 3 & HapМap & I & START -1240 & $a>g$ & 0.16 \\
\hline PPARBP-02 & rsl|655550 & HapMap & & STOP +2808 & $t>c$ & 0.24 \\
\hline CRK7-0I & rs2303315 & HapMap & & IVSIO + III & $t>a$ & 0.13 \\
\hline CRK7-02 & rs4404103 & HapMap & & IVSI 3 +88 & $a>g$ & 0.12 \\
\hline NEUROD2-0I & rs 12453682 & HapMap & 2 & STOP +5832 & $t>c$ & 0.28 \\
\hline PPPIRIB-0| & rs 1874228 & HapMap & & START -8372 & $g>a$ & 0.24 \\
\hline PPPIRIB-02 & rs879606 & HapМap & & START - 1797 & $g>a$ & 0.13 \\
\hline STARD3-0I & rs3817160 & dbSNP & & IVSI +33I & $c>g$ & 0.45 \\
\hline CAB2-0I & rs2952I5I & НарМар & 3 & START -560 & $c>t$ & 0.28 \\
\hline CAB2-02 & rs907087 & $\mathrm{dbSNP}$ & & START -269 & $a>g$ & 0.46 \\
\hline CAB2-03 & rs 1565920 & $\mathrm{dbSNP}$ & & IVS5 +68I & $a>g$ & 0.38 \\
\hline CAB2-04 & rs907089 & dbSNP & & IVS5 +2668 & $a>g$ & 0.39 \\
\hline CAB2-05 & rs 1476278 & HapMap & & IVS5 +531I & $a>g$ & 0.29 \\
\hline ERBB2-0I & rs4252596 & dbSNP & & START - 657 & $c>a$ & 0.07 \\
\hline ERBB2-02 & rs2952155 & HapМap & & IVSI +5I54 & $c>t$ & 0.2 \\
\hline ERBB2-03 & rs 1810132 & HарМар & & IVS4 +300 & $t>c$ & 0.28 \\
\hline ERBB2-04 & $r s / 801200$ & HapMap & & EXI7 (1655V) & $a>g$ & 0.33 \\
\hline ERBB2-05 & rs|058808 & HapMap & & EX27 (A||70P) & $g>c$ & 0.29 \\
\hline CI7ORF37-0I & rs4252665 & HapMap & 4 & START -26 & $c>t$ & 0.06 \\
\hline GRB7-0I & rs8192704 & HapМap & & IVS2 + 13 & $g>a$ & 0.16 \\
\hline GRB7-02 & rs | |078921 & dbSNP & & STOP +5330 & $c>a$ & 0.26 \\
\hline ZNFNIA3-0I & rs90709| & HapМар & & START -36I & $c>t$ & 0.47 \\
\hline ZNFNIA3-02 & rs 10445308 & HapMap & & IVS2 +4027 & $c>t$ & 0.48 \\
\hline
\end{tabular}

Sixteen SNPs were HapMap tSNPs, one was a HapMap singleton (ERBB2-04) and six were randomly selected from the dbSNP database. 
Table 2 Genotype frequencies, minor allele frequencies (MAF) and P-values for 23 SNPs genotyped in 2275 women with breast cancer and 2280 controls

\begin{tabular}{|c|c|c|c|c|c|c|c|}
\hline SNP & Series & Number genotyped & MAF & Common homozygote & Heterozygote & Rare homozygote & $P$-value ${ }^{a}$ \\
\hline \multirow[t]{2}{*}{ PPARBP-0I } & Cases & 2190 & 0.20 & 1422 & 665 & 103 & 0.85 \\
\hline & Controls & 2274 & & $|48|$ & 694 & 99 & \\
\hline \multirow[t]{2}{*}{ PPARBP-02 } & Cases & 2181 & 0.19 & $|42|$ & 675 & 85 & 0.47 \\
\hline & Controls & 2273 & & 1516 & 665 & 92 & \\
\hline \multirow[t]{2}{*}{ CRK7-0I } & Cases & 2186 & 0.14 & 1658 & 499 & 29 & 0.36 \\
\hline & Controls & 2273 & & 1685 & 551 & 37 & \\
\hline \multirow[t]{2}{*}{ CRK7-02 } & Cases & 2193 & 0.10 & 1797 & 379 & 17 & 0.79 \\
\hline & Controls & 2275 & & 1859 & 394 & 22 & \\
\hline \multirow[t]{2}{*}{ NEUROD2-0I } & Cases & 2180 & 0.31 & 1020 & 941 & 219 & 0.4 \\
\hline & Controls & 2271 & & 1090 & 937 & 244 & \\
\hline \multirow[t]{2}{*}{ PPPIRIB-0I } & Cases & 2150 & 0.27 & 1152 & 833 & 165 & 0.95 \\
\hline & Controls & 2245 & & 1210 & 860 & 175 & \\
\hline \multirow[t]{2}{*}{ PPPIRIB-02 } & Cases & 2085 & 0.17 & 1435 & 585 & 65 & 0.94 \\
\hline & Controls & 2198 & & 1520 & 607 & 71 & \\
\hline \multirow[t]{2}{*}{ STARD3-0I } & Cases & 2158 & 0.22 & 1303 & 736 & 119 & 0.96 \\
\hline & Controls & 2266 & & 1377 & 767 & 122 & \\
\hline \multirow[t]{2}{*}{ CAB2-0I } & Cases & 2184 & 0.32 & 1042 & 923 & 219 & 0.71 \\
\hline & Controls & 2276 & & 1064 & 969 & 243 & \\
\hline \multirow[t]{2}{*}{ CAB2-02 } & Cases & 1923 & 0.31 & 930 & 801 & 192 & 0.84 \\
\hline & Controls & 2027 & & 961 & 859 & 207 & \\
\hline \multirow[t]{2}{*}{ CAB2-03 } & Cases & 2179 & 0.33 & 995 & 953 & 231 & 0.85 \\
\hline & Controls & 2274 & & 1024 & 1014 & 236 & \\
\hline \multirow[t]{2}{*}{ CAB2-04 } & Cases & 2185 & 0.34 & 961 & 969 & 255 & 0.78 \\
\hline & Controls & 2269 & & 974 & 1025 & 270 & \\
\hline \multirow[t]{2}{*}{ CAB2-05 } & Cases & 2038 & 0.35 & 901 & 890 & 247 & 0.58 \\
\hline & Controls & 2157 & & 919 & 971 & 267 & \\
\hline \multirow[t]{2}{*}{ ERBB2-0I } & Cases & 2023 & 0.13 & 1548 & 433 & 42 & 0.14 \\
\hline & Controls & 2189 & & 1645 & 511 & 33 & \\
\hline \multirow[t]{2}{*}{ ERBB2-02 } & Cases & 2040 & 0.26 & 1162 & 738 & 140 & 0.45 \\
\hline & Controls & 2205 & & 1219 & 839 & 147 & \\
\hline \multirow[t]{2}{*}{ ERBB2-03 } & Cases & 2050 & 0.32 & 969 & 861 & 220 & 0.69 \\
\hline & Controls & 2208 & & 1022 & 956 & 230 & \\
\hline \multirow[t]{2}{*}{ ERBB2-04 } & Cases & 1999 & 0.25 & 1134 & 752 & 113 & 0.67 \\
\hline & Controls & 2154 & & 1229 & 791 & 134 & \\
\hline \multirow[t]{2}{*}{ ERBB2-05 } & Cases & 2025 & 0.33 & 916 & 875 & 234 & 0.47 \\
\hline & Controls & 2180 & & 960 & 982 & 238 & \\
\hline \multirow[t]{2}{*}{ CI7ORF37-0I } & Cases & 2169 & 0.03 & 1997 & 172 & 0 & 0.16 \\
\hline & Controls & 2259 & & 2108 & 150 & I & \\
\hline \multirow[t]{2}{*}{ GRB7-0I } & Cases & 2188 & 0.13 & 1676 & 474 & 38 & 0.36 \\
\hline & Controls & 2273 & & 1703 & 533 & 37 & \\
\hline \multirow[t]{2}{*}{ GRB7-02 } & Cases & 2171 & 0.34 & 954 & 969 & 248 & 0.85 \\
\hline & Controls & 2269 & & 983 & 1032 & 254 & \\
\hline \multirow[t]{2}{*}{ ZNFNIA3-0I } & Cases & 2088 & 0.49 & 561 & 1002 & 525 & 0.97 \\
\hline & Controls & 2214 & & 600 & 1055 & 559 & \\
\hline ZNFNIA3-02 & Cases & 2172 & 0.48 & 589 & 1086 & 497 & 0.99 \\
\hline & Controls & 2278 & & 620 & 1140 & 518 & \\
\hline
\end{tabular}

${ }^{a}$ Test for heterogeneity of genotype frequencies between cases and controls ( $\left.2 \mathrm{df}\right)$.

nor were there any differences between cases and controls for the individual haplotype frequencies.

\section{DISCUSSION}

We used a comprehensive SNP tagging approach using the publicly available HapMap data, complemented by the random selection of SNPs from dbSNP, to determine if common variation in the ERBB2 amplicon is involved in breast cancer susceptibility. A total of 23 SNPs in 4 LD blocks were genotyped; we saw no association between any of the genotypes or associated haplotypes and risk of breast cancer.

We could have failed to observe a true association because of inadequate tagging, insufficient statistical power, or the effect of confounders. The selection of tagging SNPs is most reliable where the region of interest has been resequenced in a sample of individuals sufficiently large to identify all common variants. Such data were not available for this region, and it is possible that we have not adequately tagged an unidentified, disease-predisposing SNP. We estimated how well tSNPs would tag such unknown SNPs by performing a leave-one-out cross validation procedure on the HapMap data used for tSNP selection. Each of the 65 known SNPs were dropped in turn and tSNPs selected from the remaining SNPs within the block, thus simulating unidentified polymorphisms (Ahmadi et al, 2005). The ability of the tSNPs to tag the dropped SNP was then evaluated by calculating $r_{\mathrm{s}}^{2}$. The average $r_{\mathrm{s}}^{2}$ for all dropped SNPs was 0.91 and 59 out of the 65 dropped SNPs (91\%) were tagged with an $r_{\mathrm{s}}^{2}>0.75$. This suggests that $91 \%$ of the unknown variation was well tagged. Furthermore, it has been shown that Phase 2 HapMap data provides a robust alternative to complete re-sequencing data with minimal loss of power (De Bakker et al, 2005). After we had completed the genotyping for this study, data for phase 2 of the HapMap project were released. For 
SNP Heterozygote vs common homozygote

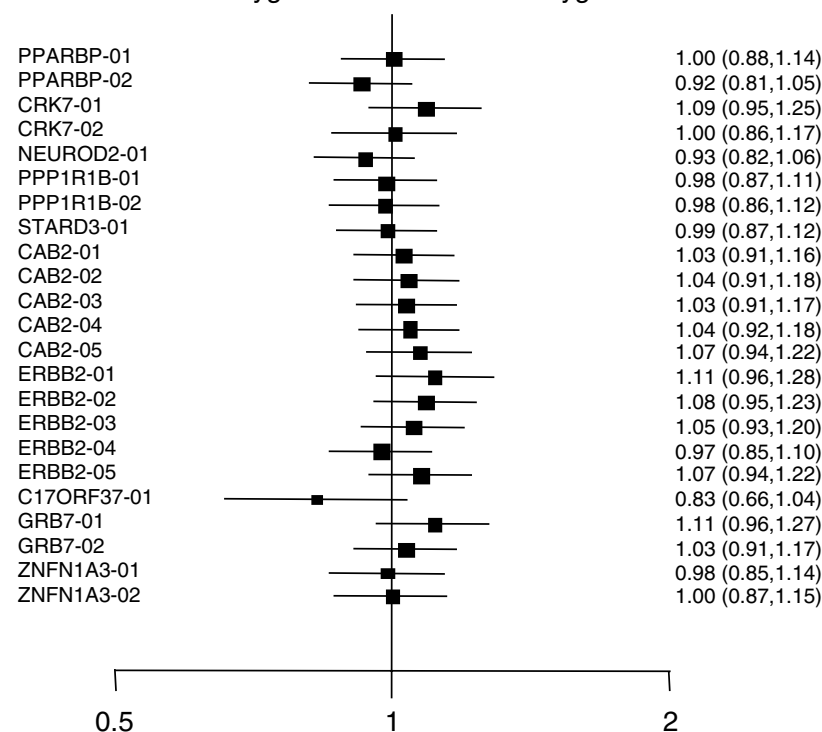

Odds ratio

\section{Rare homozygote vs common homozygote}

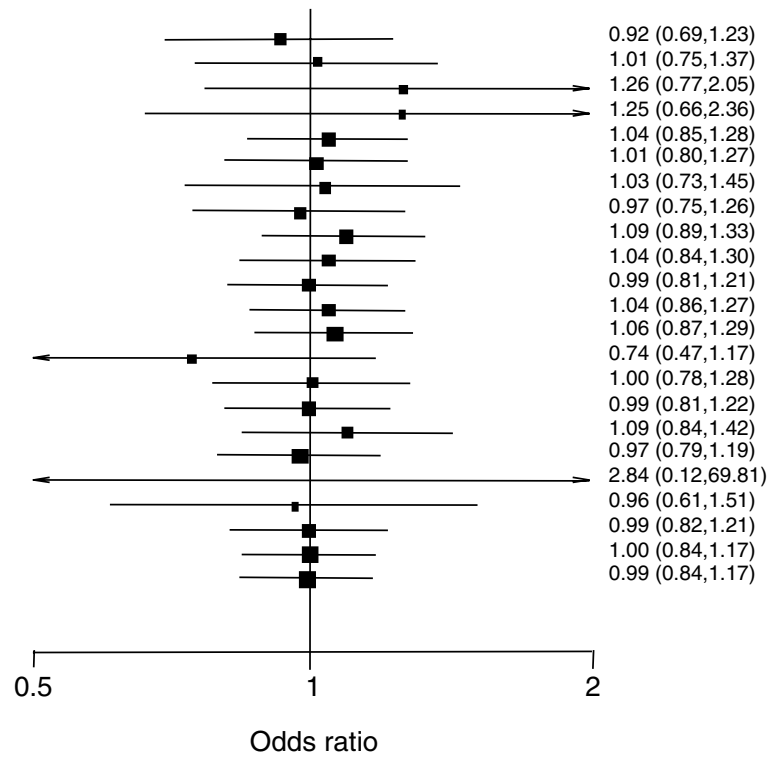

Figure 2 Genotype-specific risks for 23 SNPs genotyped in 2275 women with breast cancer and 2280 controls.

Table 3 Haplotype frequencies within LD blocks. ERBB2-04, a HapMap singleton SNP, was excluded from block 3 for haplotype analyses as it is poorly correlated with any other SNPs in the block

\begin{tabular}{|c|c|c|c|c|}
\hline Block & $\begin{array}{l}\text { Global test of } \\
\text { association }\end{array}$ & Haplotype & $\begin{array}{l}\text { Frequency in } \\
\text { controls (\%) }\end{array}$ & $P$-value \\
\hline 1 & 0.16 & $\begin{array}{l}\text {-a-t-t-a- } \\
\text {-a-c-t-a- } \\
\text {-g-t-t-a- } \\
\text {-a-t-a-a- } \\
\text {-a-t-t-g- }\end{array}$ & $\begin{array}{r}41 \\
19 \\
16 \\
13 \\
7\end{array}$ & $\begin{array}{l}0.74 \\
0.43 \\
0.24 \\
0.13 \\
0.48\end{array}$ \\
\hline 2 & 0.58 & $\begin{array}{l}-t-g-g-c- \\
-c-a-a-g- \\
-c-a-g-c-\end{array}$ & $\begin{array}{r}68 \\
17 \\
7\end{array}$ & $\begin{array}{l}0.8 \\
0.96 \\
0.41\end{array}$ \\
\hline 3 & 0.48 & $\begin{array}{l}\text {-c-a-a-a-a-c-c-t-g- } \\
\text {-t-g-g-g-g-c-t-c-c- } \\
\text {-c-a-a-a-a-a-c-t-g- } \\
\text {-t-g-g-g-g-c-c-c-c- }\end{array}$ & $\begin{array}{r}51 \\
24 \\
13 \\
6\end{array}$ & $\begin{array}{l}0.34 \\
0.24 \\
0.31 \\
0.57\end{array}$ \\
\hline 4 & 0.44 & $\begin{array}{l}-c-g-c-t-c- \\
-c-g-a-c-t- \\
-c-g-c-c-t- \\
-c-a-c-t-c-\end{array}$ & $\begin{array}{r}37 \\
28 \\
13 \\
9\end{array}$ & $\begin{array}{l}0.55 \\
0.75 \\
0.27 \\
0.19\end{array}$ \\
\hline
\end{tabular}

region A, there were now data for 35 SNPs - SNP density 1 SNP/ $4.2 \mathrm{~kb}$. We used the programme TAGGER to test the performance of our selected tSNPs on HapMap phase 2 (Paul de Bakker, http:// www.broad.mit.edu/mpg/tagger/). Mean pairwise $r^{2}\left(r_{\mathrm{p}}^{2}\right)$ was 0.92 with 31 HapMap SNPs being tagged with $r_{\mathrm{p}}^{2}>0.8$ and a minimum $r_{\mathrm{p}}^{2}$ of 0.21 . For region B there were data on 57 SNPs (1 SNP/3.3 kb). Mean $r_{\mathrm{p}}^{2}$ was 0.91 with 53 HapMap SNPs being tagged with $r_{\mathrm{p}}^{2}>0.8$ and a minimum $r_{\mathrm{p}}^{2}$ of 0.12 . These are conservative estimates since additional SNPs with undetermined tagging properties were randomly selected from dbSNP. Thus, the majority of common genetic variation is likely to have been captured, but we cannot exclude the possibility that an important common variant was missed.
PNMT is thought to regulate leptin levels and could be relevant to breast cancer biology via its effect on body weight (Harvey and Ashford, 2003; Stattin et al, 2004). None of the HapMap SNPs were in $P N M T$, raising questions regarding appropriate tagging of the gene. Ahmadi et al (2005) studied tagging patterns across 55 genes, including $P N M T$, that control the absorption, distribution, metabolism and excretion of drugs; they were able to determine that variation within $P N M T$ was adequately tagged by rs 1053651 in TCAP and rs903502 in CAB2, two HapMap SNPs that were well tagged by our set of tSNPs.

The statistical power of the study depends on the risk allele frequency, the risks conferred and the genetic mode of action (dominant, recessive, codominant). The staged approach substantially reduces genotyping costs without significantly affecting statistical power. For example, assuming that the causative SNP is tagged with $r_{\mathrm{p}}^{2}=0.8$, a type I error rate of 0.0001 and genotyping success rate of 0.95 , the staged study has $86 \%$ power to detect a dominant allele with a minor allele frequency (MAF) of 0.05 that confers a relative risk of 1.5 or $87 \%$ power to detect a dominant allele with a MAF of 0.25 that confers a relative risk of 1.3. Power to detect recessive alleles is less $-53 \%$ for an allele with a MAF of 0.25 and a relative risk of 1.5 and $71 \%$ for an allele with a MAF of 0.5 and a relative risk of 1.3. Such high power is illustrated by the narrow confidence intervals observed for odds ratios associated with genotypes: heterozygote odds ratios higher than 1.28 were excluded for all SNPs. Based on the upper confidence limits for all the risk estimates we can exclude SNPs that explain more than $0.8 \%$ of the excess familial risk of breast cancer. The possibility of variants with smaller effects on risk cannot be excluded. Similarly the possibility that there are rare variants with modest, or even large effect cannot be excluded.

Confounders are factors that are associated with both genotype and phenotype. They may bias results towards false positives and false negatives. In the context of breast cancer genetic association studies, it is difficult to envisage a true confounder. Most factors that are likely to be associated with both genotype and breast cancer will be intermediate factors, not confounders. The cases and controls used for these analyses were not matched for age (though broadly similar). However, there was no association of genotype with age in controls for any of the SNPs 
studied and age-adjusted odds ratios were similar to the unadjusted values.

Some authors have advocated the use of histopathologic or demographic data that subclassify individuals in order to identify homogeneous subsets for analysis (Rebbeck et al, 2004). In the absence of any main effect or strong biological rationale, we have not carried out subgroup analyses. The number of possible post hoc, subgroup analyses is large and there is a strong possibility that one or more tests will be statistically significant simply by chance (Colhoun et al, 2003; Pharoah et al, 2005). Much larger sample sizes would be required to obtain reliable results. Nor did we test for SNP-SNP or SNP-environment interactions as the number of such interactions is very large - there are over 2000 possible two- and three-way interactions between the 23 genotyped common SNPs - and a clear strategy on how to best approach interactions has yet to be defined (Ritchie et al, 2003; Hunter, 2005).

We found no evidence that common genetic variation in the $E R B B 2$ amplicon is associated with an altered risk of breast cancer. The strategy of selecting candidate genes from regions that are often amplified was not successful here, but we have only evaluated a small proportion of the genome that is commonly somatically altered in breast cancer. The search for common susceptibility alleles for breast and the other common cancers using a candidate

\section{REFERENCES}

Ahmadi KR, Weale ME, Xue ZY, Soranzo N, Yarnall DP, Briley JD, Maruyama Y, Kobayashi M, Wood NW, Spurr NK, Burns DK, Roses AD, Saunders AM, Goldstein DB (2005) A single-nucleotide polymorphism tagging set for human drug metabolism and transport. Nat Genet 37: $84-$ 89

Benusiglio PR, Lesueur F, Luccarini C, Conroy DM, Shah M, Easton DF, Day NE, Dunning AM, Pharoah PD, Ponder BA (2005) Common ERBB2 polymorphisms and risk of breast cancer in a white British population: a case-control study. Breast Cancer Res 7: R204-R209

Bottner A, Haidan A, Eisenhofer G, Kristensen K, Castle AL, Scherbaum WA, Schneider H, Chrousos GP, Bornstein SR (2000) Increased body fat mass and suppression of circulating leptin levels in response to hypersecretion of epinephrine in phenylethanolamine- $N$-methyltransferase (PNMT)-overexpressing mice. Endocrinology 141: 4239-4246

Cardon LR, Abecasis GR (2003) Using haplotype blocks to map human complex trait loci. Trends Genet 19: $135-140$

Colhoun HM, McKeigue PM, Davey SG (2003) Problems of reporting genetic associations with complex outcomes. Lancet 361: 865-872

De Bakker PI, Yelensky R, Pe'er I, Gabriel SB, Daly MJ, Altshuler D (2005) Efficiency and power in genetic association studies. Nat Genet 37: $1217-1223$

Dite GS, Jenkins MA, Southey MC, Hocking JS, Giles GG, McCredie MR, Venter DJ, Hopper JL (2003) Familial risks, early-onset breast cancer, and BRCA1 and BRCA2 germline mutations. J Natl Cancer Inst 95: $448-457$

Futreal PA, Coin L, Marshall M, Down T, Hubbard T, Wooster R, Rahman N, Stratton MR (2004) A census of human cancer genes. Nat Rev Cancer 4: $177-183$

Gabriel SB, Schaffner SF, Nguyen H, Moore JM, Roy J, Blumenstiel B, Higgins J, DeFelice M, Lochner A, Faggart M, Liu-Cordero SN, Rotimi C, Adeyemo A, Cooper R, Ward R, Lander ES, Daly MJ, Altshuler D (2002) The structure of haplotype blocks in the human genome. Science 296: $2225-2229$

Gibbs RA, Belmont JW, Hardenbol P, Willis TD, Yu F, Yang H, Ch'ang LY, Huang W, Liu B, Shen Y, Tam PK, Tsui LC, Waye MM, Wong JT, Zeng C, Zhang Q, Chee MS, Galver LM, Kruglyak S, Murray SS, Oliphant AR, Montpetit A, Hudson TJ, Chagnon F, Ferretti V, Leboeuf M, Phillips MS, Verner A, Kwok PY, Duan S, Lind DL, Miller RD, Rice JP, Saccone NL, Taillon-Miller P, Xiao M, Nakamura Y, Sekine A, Sorimachi K, Tanaka T, Tanaka Y, Tsunoda T, Yoshino E, Bentley DR, Deloukas P, Hunt S, Powell D, Altshuler D, Gabriel SB, Zhang H, Matsuda I, Fukushima Y, Macer DR, Suda E, Rotimi CN, Adebamowo CA, Aniagwu T, Marshall PA, Matthew O, Nkwodimmah C, Royal CD, Leppert MF, Dixon M, Stein gene approach has been notable for its lack of success. However, there are many, possibly thousands, of candidate genes of which only tens or hundreds have been comprehensively assessed for susceptibility. Advances in our understanding of human genomic architecture with rapid developments in high-throughput genotyping technology have made empirical, genome-wide association (GWA) studies feasible. The results of the first GWA scans in breast and colorectal cancer are expected in the near future. These should provide evidence whether or not common susceptibility variants exist. They may also provide an indication whether candidate gene studies remain a valid approach and, if so, what the likely candidates are.

\section{ACKNOWLEDGEMENTS}

PRB is supported by the Ligue Genevoise contre le Cancer, Switzerland (N/Ref 0208). BAJP is a Gibb Fellow, DFE is a Principal Fellow and PDP is a Senior Clinical Research Fellow of Cancer Research United Kingdom. This work was funded by Cancer Research United Kingdom. We are grateful to Craig Luccarini for his laboratory expertise and to Shahana Ahmed and Oluseun Ajai for their technical help.
LD, Cunningham F, Kanani A, Thorisson GA, Chakravarti A, Chen PE, Cutler DJ, Kashuk CS, Donnelly P, Marchini J, McVean GA, Myers SR, Cardon LR, Abecasis GR, Morris A, Weir BS, Mullikin JC, Sherry ST, Feolo M, Altshuler D, Daly MJ, Schaffner SF, Qiu R, Kent A, Dunston GM, Kato K, Niikawa N, Knoppers BM, Foster MW, Clayton EW, Wang VO, Watkin J, Gibbs RA, Belmont JW, Sodergren E, Weinstock GM, Wilson RK, Fulton LL, Rogers J, Birren BW, Han H, Wang H, Godbout M, Wallenburg JC, L'Archeveque P, Bellemare G, Todani K, Fujita T, Tanaka S, Holden AL, Lai EH, Collins FS, Brooks LD, McEwen JE, Guyer MS, Jordan E, Peterson JL, Spiegel J, Sung LM, Zacharia LF, Kennedy K, Dunn MG, Seabrook R, Shillito M, Skene B, Stewart JG, Valle DL, Jorde LB, Belmont JW, Chakravarti A, Cho MK, Duster T, Foster MW, Jasperse M, Knoppers BM, Kwok PY, Licinio J, Long JC, Marshall PA, Ossorio PN, Wang VO, Rotimi CN, Royal CD, Spallone P, Terry SF, Lander ES, Lai EH, Nickerson DA, Altshuler D, Bentley DR, Boehnke M, Cardon LR, Daly MJ, Deloukas P, Douglas JA, Gabriel SB, Hudson RR, Hudson TJ, Kruglyak L, Kwok PY, Nakamura Y, Nussbaum RL, Royal CD, Schaffner SF, Sherry ST, Stein LD, Tanaka T (2003) The International HapMap Project. Nature 426: 789-796

Han DC, Shen TL, Guan JL (2001) The Grb7 family proteins: structure, interactions with other signaling molecules and potential cellular functions. Oncogene 20: 6315-6321

Harvey J, Ashford ML (2003) Leptin in the CNS: much more than a satiety signal. Neuropharmacology 44: 845-854

Hunter DJ (2005) Gene-environment interactions in human diseases. Nat Rev Genet 6: $287-298$

Kauraniemi P, Barlund M, Monni O, Kallioniemi A (2001) New amplified and highly expressed genes discovered in the ERBB2 amplicon in breast cancer by cDNA microarrays. Cancer Res 61: 8235-8240

Kauraniemi P, Kuukasjarvi T, Sauter G, Kallioniemi A (2003) Amplification of a 280-kilobase core region at the ERBB2 locus leads to activation of two hypothetical proteins in breast cancer. Am J Pathol 163: $1979-1984$

Ko TK, Kelly E, Pines J (2001) CrkRS: a novel conserved Cdc2-related protein kinase that colocalises with SC35 speckles. J Cell Sci 114: 2591 2603

Nezu M, Nishigaki M, Ishizuka T, Kuwahara Y, Tanabe C, Aoyagi K, Sakamoto H, Saito Y, Yoshida T, Sasaki H, Terada M (2002) Identification of the $\mathrm{CAB} 2 / \mathrm{hCOS} 16$ gene required for the repair of DNA double-strand breaks on a core amplified region of the 17q12 locus in breast and gastric cancers. Jpn J Cancer Res 93: 1183-1186

Orsetti B, Nugoli M, Cervera N, Lasorsa L, Chuchana P, Ursule L, Nguyen C, Redon R, Du MS, Rodriguez C, Theillet C (2004) Genomic and expression 
profiling of chromosome 17 in breast cancer reveals complex patterns of alterations and novel candidate genes. Cancer Res 64: 6453-6460

Pharoah PD, Antoniou A, Bobrow M, Zimmern RL, Easton DF, Ponder BA (2002) Polygenic susceptibility to breast cancer and implications for prevention. Nat Genet 31: 33-36

Pharoah PD, Dunning AM, Ponder BA, Easton DF (2004) Association studies for finding cancer-susceptibility genetic variants. Nat Rev Cancer 4: $850-860$

Pharoah PD, Dunning AM, Ponder BA, Easton DF (2005) The reliable identification of disease-gene associations. Cancer Epidemiol Biomarkers Prev 14: 1362

Rebbeck TR, Martinez ME, Sellers TA, Shields PG, Wild CP, Potter JD (2004) Genetic variation and cancer: improving the environment for publication of association studies. Cancer Epidemiol Biomarkers Prev 13: $1985-1986$

Rebollo A, Schmitt C (2003) Ikaros, Aiolos and Helios: transcription regulators and lymphoid malignancies. Immunol Cell Biol 81: 171-175

Risch NJ (2000) Searching for genetic determinants in the new millennium. Nature 405: 847-856

Ritchie MD, White BC, Parker JS, Hahn LW, Moore JH (2003) Optimization of neural network architecture using genetic programming improves detection and modeling of gene-gene interactions in studies of human diseases. BMC Bioinformat 4: 28
Schaid DJ, Rowland CM, Tines DE, Jacobson RM, Poland GA (2002) Score tests for association between traits and haplotypes when linkage phase is ambiguous. Am J Hum Genet 70: 425-434

Stattin P, Soderberg S, Biessy C, Lenner P, Hallmans G, Kaaks R, Olsson T (2004) Plasma leptin and breast cancer risk: a prospective study in northern sweden. Breast Cancer Res Treat 86: 191-196

Stram DO (2004) Tag SNP selection for association studies. Genet Epidemiol 27: 365 - 374

Strauss III JF, Kishida T, Christenson LK, Fujimoto T, Hiroi H (2003) START domain proteins and the intracellular trafficking of cholesterol in steroidogenic cells. Mol Cell Endocrinol 202: 59-65

Tabor HK, Risch NJ, Myers RM (2002) Opinion: candidate-gene approaches for studying complex genetic traits: practical considerations. Nat Rev Genet 3: $391-397$

Willis S, Hutchins AM, Hammet F, Ciciulla J, Soo WK, White D, van der SP, Henderson MA, Gish K, Venter DJ, Armes JE (2003) Detailed gene copy number and RNA expression analysis of the 17q12-23 region in primary breast cancers. Genes Chromosomes Cancer 36: 382-392

Zhu Y, Qi C, Jain S, Le Beau MM, Espinosa R, III, Atkins GB, Lazar MA, Yeldandi AV, Rao MS, Reddy JK (1999) Amplification and overexpression of peroxisome proliferator-activated receptor binding protein (PBP/PPARBP) gene in breast cancer. Proc Natl Acad Sci USA 96: 10848 10853 